\title{
Elementary, My Dear Watson: The Use of Artificial Intelligence in Marketing Research: An Abstract
}

\author{
Christine Pitt, Theresa Eriksson, Amir Dabirian, and Joseph Vella
}

\begin{abstract}
In this paper, the authors demonstrate how IBM Watson, a super computer that uses artificial intelligence (AI), can be used in academic and managerial research. A brief description of how Watson originated and operates is followed by four examples of how Watson can be used in academic marketing research. The first two examples use Watson's personality and insight services to analyze qualitative depth interviews. The last two examples use Watson's emotion and sentiment analysis on textual data and qualitative depth interviews. These examples emphasize the value of Watson in the age of big data and its ability to analyze issues that would otherwise be too complex. The paper concludes with limitations, managerial implications, and future research.
\end{abstract}

\author{
C. Pitt $(\bowtie) \cdot$ A. Dabirian \\ Royal Institute of Technology, Stockholm, Sweden \\ e-mail: christinepitt91@gmail.com; amir.dabirian@indek.kth.se \\ T. Eriksson \\ Luleå University of Technology, Luleå, Sweden \\ e-mail: tess@blink.se \\ J. Vella \\ University of Malta, Msida, Malta \\ e-mail: joseph.m.vella@um.edu.mt
}

